\title{
Phase Equilibrium in the Fe-Cr-Nb Alloys
}

\author{
S. Mansour ${ }^{(1)}$, N. Boutarek ${ }^{(1)}$, H. Aid ${ }^{(1)}$, S.E .Amara ${ }^{(2)}$ \\ (1) Laboratoire des Sciences et Génie des Matériaux, Faculté de Génie Mécanique et Génie des Procédés, \\ (2) Laboratoire d'Electrochimie-Corrosion Métallurgie et Chimie Minérale, Faculté de Chimie, \\ USTHB, BP 32 El Alia, 16111 Bab Ezzouar, Alger, Algérie. \\ E-mail: nboutarek@yahoo.fr
}

\begin{abstract}
The present work is a continuation of research on alloys based on iron, aiming at understanding the solidification behaviour of $\mathrm{Fe}-\mathrm{Cr}-\mathrm{Nb}$ alloys. Ternary Fe-Cr-Nb alloys with different concentrations were arcmelted and systematically characterized by means of; differential thermal analysis, optical and scanning electron microscopy coupled to an energy dispersive X-ray microprobe analysis and X-ray diffraction.

For the first time, we suspect the presence of a metastable $\alpha$-phase in Fe-rich alloy. For higher vanadium and niobium contents a competition between two eutectics, E2 and E3, is clearly shown according to the observed microstructures and the solidification sequences.
\end{abstract}

\section{Keywords:}

Ternary diagram, Phase Equilibrium, differential thermal analysis, phase transition, solidification sequences.

\section{INTRODUCTION}

Recent years have witnessed a growing demand for structural materials capable of withstanding oxidizing environments at high temperatures in various areas, including aviation turbine. These materials must have, besides an excellent resistance to oxidation at high temperature, high melting point and mechanical properties depending on temperature control [1,

\% $\mathrm{b}$ overcome these limitations and further performance, the use of intermetallics could open new avenues to exploit appropriate combinations.

New systems of intermetallic compounds with more complex structures and melting points are higher ups guidance for developing new material systems.

In the present work, the thermal and microsructural behavior of Fe-Cr-Nb alloys in the Fe-rich corner have been studied aiming at paying attention to the equilibrium intermetallic phases, the distribution of phases, their morphology and microstructures The major difficulty in this work is to explain the microstructures observed considering the recorded thermograms.

Also, Note that the elements $\mathrm{Fe}, \mathrm{Cr}$ and $\mathrm{Nb}$ have attractive properties in points of view of stability at high temperature, mechanical properties and resistance to the environment [3-

\section{2] EXPERIMENTAL}

Series of ternary iron-chromium-niobium alloys were prepared using pure iron of $99.99 \%$ purity and pure chromium and niobium of $99.9 \%$ purity. The stoichiometric mixtures of iron, chromium and niobium chromium were arc melted (Buhler MAM1 furnace type) several times (minimum 4 times), to ensure the homogeneity of our samples, in a pure argon gas atmosphere $(5 N)$ in a water-cooled copper crucible.

Differential thermal analysis (DTA) specimens cut as small cylinders with $\phi=4 \mathrm{~mm} \times 10 \mathrm{~mm}$ in length (1 g maximum) were prepared from the alloys, and a Netzsch 404 S DTA apparatus was used for the thermal analysis.
DTA measurements were taken in the cooling regime. The specimens were heated at $10 \mathrm{~K} \cdot \mathrm{min}^{-1}$, up to a maximum temperature of $1550{ }^{\circ} \mathrm{C}$, and cooled (at $10 \mathrm{~K} \cdot \mathrm{min}^{-1}$ ) to room temperature. The heating and cooling were in an argon (5N) flow gas atmosphere $\left(150 \mathrm{ml} \cdot \mathrm{min}^{-1}\right)$ to prevent samples from oxidation. The temperature was measured using a type $\mathrm{S}$ thermocouple and $\mathrm{Al}_{2} \mathrm{O}_{3}$ powder was used as the reference.

Ingots were cut, polished and observed by optical and scanning electron microscopy (SEM). The microstructures of the alloys were checked using a Zeiss ICM 405 optical microscope and a Jeol JSM 63603LV scanning electron microscope. The composition (semi-quantitative) of the phases was estimated by means of Energy Dispersive $X$ Ray Spectrometry (EDS) analysis. The EDS analysis of different phases was performed under controlled conditions (counts. $\mathrm{s}^{-1}$ and size of phases) in order to be able to compare the results from different specimens. Prior to microscopic observations, samples were treated with nital solution ( $3 \mathrm{ml}$ of $\mathrm{HNO}_{3}$ in $100 \mathrm{ml}$ of ethanol) for $30 \mathrm{~s}$ at room temperature.

For phase identification and crystallinity analysis, X-ray diffraction (XRD) experiments were carried out using a Philips PPW1730 diffractometer and a scanning rate of $0.004^{\circ} \mathrm{s}^{-1}$ over the range $2 \theta=20-140^{\circ}$, with unfiltered $\mathrm{Cu}-\mathrm{K}_{\alpha}$ radiation $(\lambda=1.5406 \AA \hat{)})$, operating at $45 \mathrm{kV}$ and $45 \mathrm{~mA}$.

\section{RESULTS AND DISCUSSION}

Table 1 shows the alloy compositions, the transformation temperatures and the solidification sequences in relation with the observed microstructures. The a-solid solution is identified as the primary crystallisation phase (EDS 1, Fig.1b and Fig.4b) in all studied compositions.

The DTA results and the microscopic observations allow us to distinguish three $\mathrm{FeCrNb}$ alloys families.

This is an Open Access article distributed under the terms of the Creative Commons Attribution-Noncommercial License (http://creativecommons.org/licenses/by-nc/3.0/), which permits unrestricted use, distribution, and reproduction in any noncommercial medium, provided the original work is properly cited. 


\begin{tabular}{|c|c|c|c|c|c|}
\hline \multirow{2}{*}{ Alloys } & \multicolumn{3}{|c|}{$\begin{array}{l}\text { Compositions (at.\%) } \\
\text { (EDS analysis) }\end{array}$} & \multirow{2}{*}{$\begin{array}{c}\text { Transformation } \\
\text { Temperatures }\end{array}$} & \multirow{2}{*}{ Solidification sequences } \\
\hline & $\mathrm{Fe}$ & $\mathrm{Cr}$ & $\mathrm{Nb}$ & & \\
\hline \multirow{4}{*}{$\begin{array}{c}1 \\
\mathrm{Fe}_{95} \mathrm{Cr}_{3.5} \mathrm{Nb}_{1.5}\end{array}$} & \multirow{4}{*}{94.76} & \multirow{4}{*}{3.42} & \multirow{4}{*}{1.83} & $1410^{\circ} \mathrm{C}$ & $L \leftrightarrow \alpha$ \\
\hline & & & & $1290^{\circ} \mathrm{C}$ & $\alpha \leftrightarrow \alpha^{\prime}$ \\
\hline & & & & $835^{\circ} \mathrm{C}$ & $\mathrm{L} \leftrightarrow$ eutectic E1 \\
\hline & & & & $777^{\circ} \mathrm{C}$ & Magnetic transformation \\
\hline \multirow{4}{*}{$\begin{array}{c}2 \\
\mathrm{Fe}_{85} \mathrm{Cr}_{10} \mathrm{Nb}_{5}\end{array}$} & \multirow{4}{*}{81.95} & \multirow{4}{*}{10} & \multirow{4}{*}{8.05} & $1390^{\circ} \mathrm{C}$ & $L \leftrightarrow \alpha$ \\
\hline & & & & $1345^{\circ} \mathrm{C}$ & $\mathrm{L} \leftrightarrow$ eutectic E2 \\
\hline & & & & $1310^{\circ} \mathrm{C}$ & $\alpha \leftrightarrow \alpha^{\prime}$ \\
\hline & & & & $750^{\circ} \mathrm{C}$ & Magnetic transformation \\
\hline \multirow{3}{*}{$\mathrm{Fe}_{75} \mathrm{Cr}_{16.5}^{3} \mathrm{Nb}_{8.5}$} & \multirow{3}{*}{74.94} & \multirow{3}{*}{17.57} & \multirow{3}{*}{7.48} & $1420^{\circ} \mathrm{C}$ & $\mathrm{L} \leftrightarrow \alpha$ \\
\hline & & & & $1390^{\circ} \mathrm{C}$ & $\mathrm{L} \leftrightarrow$ eutectic E3 \\
\hline & & & & 1365 & $\mathrm{~L} \leftrightarrow$ eutectic E2 \\
\hline \multirow{3}{*}{$\begin{array}{c}4 \\
\mathrm{Fe}_{65} \mathrm{Cr}_{23.5} \mathrm{Nb}_{11.5}\end{array}$} & \multirow{3}{*}{70.05} & \multirow{3}{*}{23.22} & \multirow{3}{*}{6.73} & $1405^{\circ} \mathrm{C}$ & $\mathrm{L} \leftrightarrow \alpha$ \\
\hline & & & & $1390^{\circ} \mathrm{C}$ & $\mathrm{L} \leftrightarrow$ eutectic E3 \\
\hline & & & & $1340^{\circ} \mathrm{C}$ & $\mathrm{L} \leftrightarrow$ eutectic E2 \\
\hline
\end{tabular}

Table 1: Compositions, transformation temperatures and solidification sequences of the studied alloy.

\subsection{Alloy1}

The microstructure (Fig.1) shows $\alpha(\mathrm{Fe})$ dendritic structure. The Interdendritic space in this case remains rather limited.

The microstructure (Fig.1b) observed at large magnification, is characteristic of the homogeneous matrix composed primarily of iron admitted a low substitution of chromium and niobium. This is probably a solid solution $\alpha(\mathrm{Fe}-\mathrm{Cr})$ as predicted by the binary $\mathrm{Fe}-\mathrm{Cr}$ phase diagram [7]. Chemical analysis by means of EDS of the interdendritic space (clear phase) shows a biphasic structure formed from $\alpha(\mathrm{Fe})$ and a very fine iron-based phase which is $\mathrm{Nb}$-rich.

The thermogram of the alloy 1 (Fig. 2) shows four peaks at $1410^{\circ} \mathrm{C}, 1290^{\circ} \mathrm{C}, 835^{\circ} \mathrm{C}$ and $777^{\circ} \mathrm{C}$.

These temperatures are attributed respectively to the transformations: formation of primary dendrites $(L \leftrightarrow \alpha)$, rearrangement of part of the primary phase $\alpha$ to $\alpha^{\prime}\left(\alpha \leftrightarrow \alpha^{\prime}\right)$ [8], solidification of the interdendritic liquid showing a globular aspect (eutectic E1 transformation) and occurring of the magnetic transformation.

Note that the shape of the second $\left(1290^{\circ} \mathrm{C}\right)$ and last $\left(777^{\circ} \mathrm{C}\right)$ peak reflect the presence of second order transformations ( $\alpha \rightarrow \alpha^{\prime}$ transformation and magnetic). However, the low intensity of the third peak at $835^{\circ} \mathrm{C}$ (Fig.2) is related to the low percentage of interdendritic space (Fig.1).

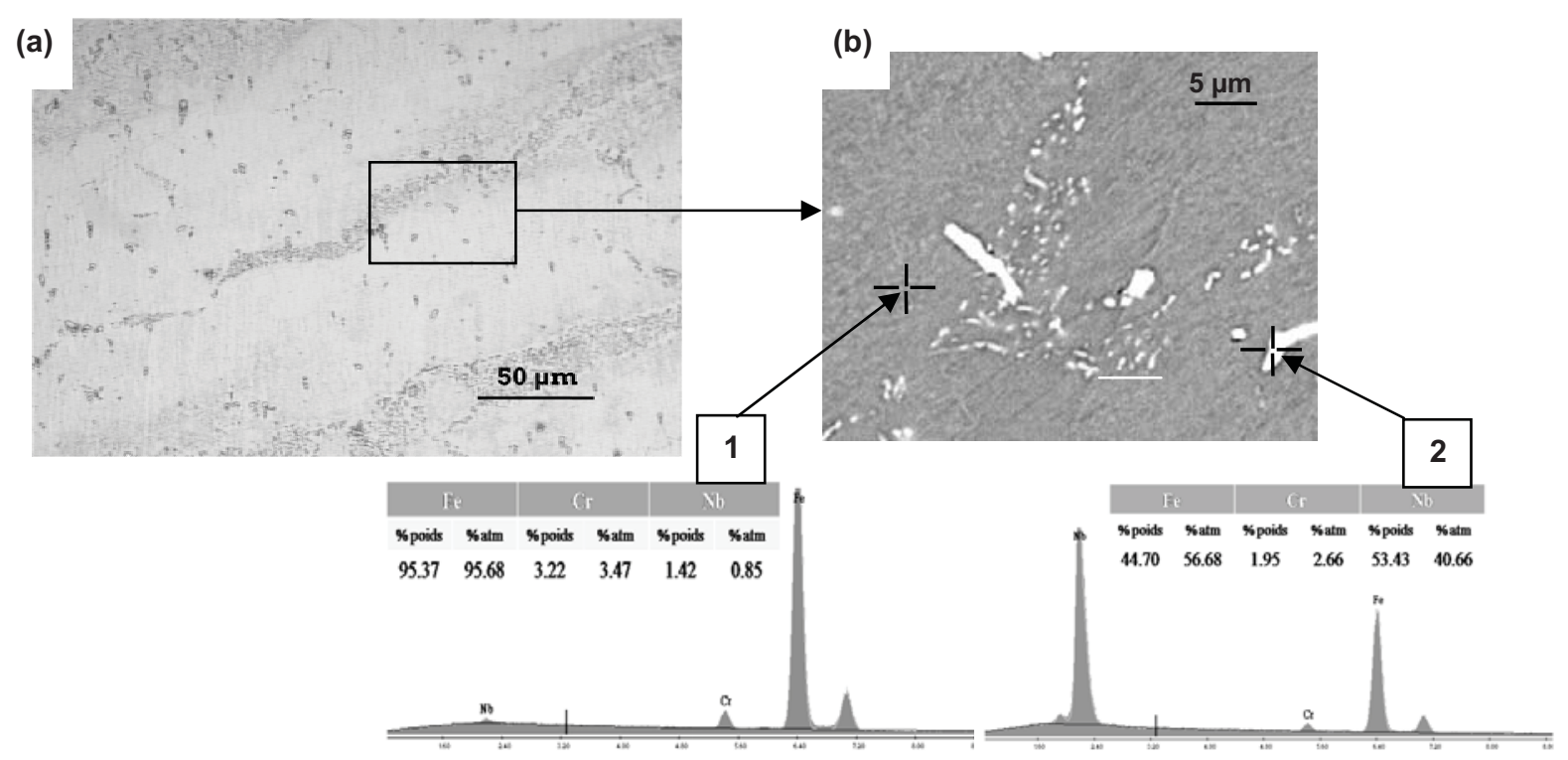

Figure 1: Alloy 1 SEM microstructure, EDS spectrum semi-quantitative analysis from:

(1) Gray area, (2) Clear area. 


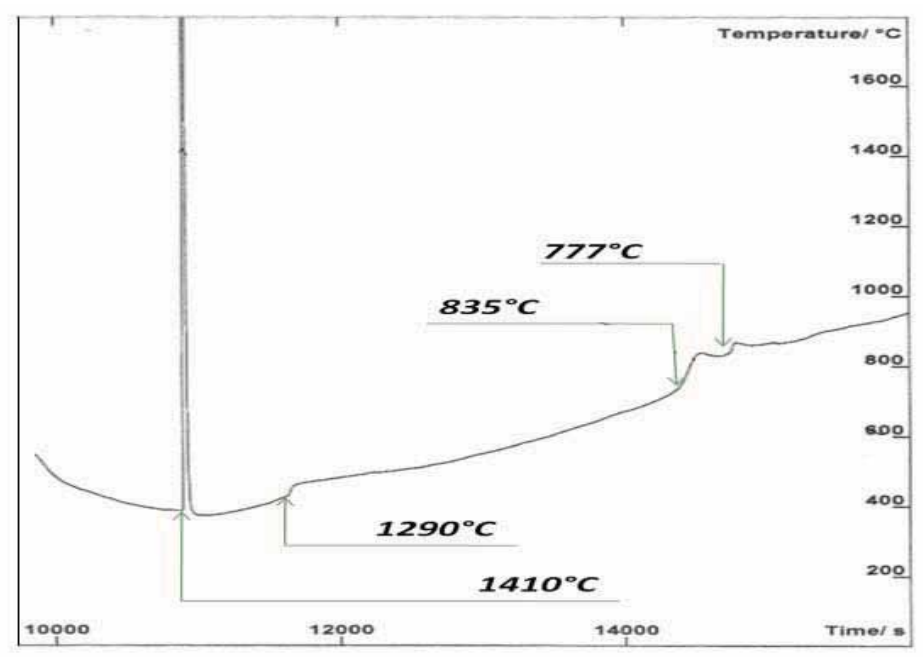

Figure 2: DTA curve of the alloy 1 on cooling with a heating rate of $10 \mathrm{~K} \cdot \mathrm{min}^{-1}$, showing four peaks at $1410^{\circ} \mathrm{C}, 1290^{\circ} \mathrm{C}$, $835^{\circ} \mathrm{C}$ and $777^{\circ} \mathrm{C}$.

\subsection{Alloy 2}

The DTA curve obtained for the alloy 2 (Fig. 3) reveals the presence of four exothermic peaks at $1390^{\circ} \mathrm{C}, 1345^{\circ} \mathrm{C}$, $1310^{\circ} \mathrm{C}$ and $750^{\circ} \mathrm{C}$. Correlated with the conclusions made on the crystallization of the sample 1 , we suggest that the first peak $\left(1390^{\circ} \mathrm{C}\right)$ correspond to the solidification of the primary phase $(L \leftrightarrow \alpha)$, the third $\left(1310^{\circ} \mathrm{C}\right)$ to the $\alpha \rightarrow \alpha^{\prime}$ transformation, and finally the last peak $\left(750^{\circ} \mathrm{C}\right)$ to the magnetic transformation.

Note, that the shape of the second peak raised to $1345{ }^{\circ} \mathrm{C}$ and that it is not detected in Sample 1. This reflects the occurrence of a new transformation.

The microstructure of this alloy (Fig. 4b) confirms this assumption; it reveals dendrites (dark 1) and an eutectic structure (clear 2) located in the interdendritic space.
According to the matrix chemical analysis (Fig. 4b, EDS1) we identified this phase to the $\alpha$-solid solution ( $\mathrm{Fe}-\mathrm{Cr}$ )

The interdendritic space (Fig. 4b, EDS2) shows a biphasic structure formed from a dark contrast with a chemical composition close to the $\alpha$ one, and a clear contrast which we could assign to the crystallization of an iron-chromiumniobium phase. The interdendritic space in this case corresponds to almost $40 \% \mathrm{vol}$. of the amount of the sample.

According to our experimental results (the important size of second DTA peak associated to the SEM interdendritic microstructure which reveals a biphasic structure, the second DTA peak may be associated with the crystallization of an eutectic ( $\alpha /$ pseudo-binary phase) or (a/ternary Fe-Cr-Nb phase), denoted E2.

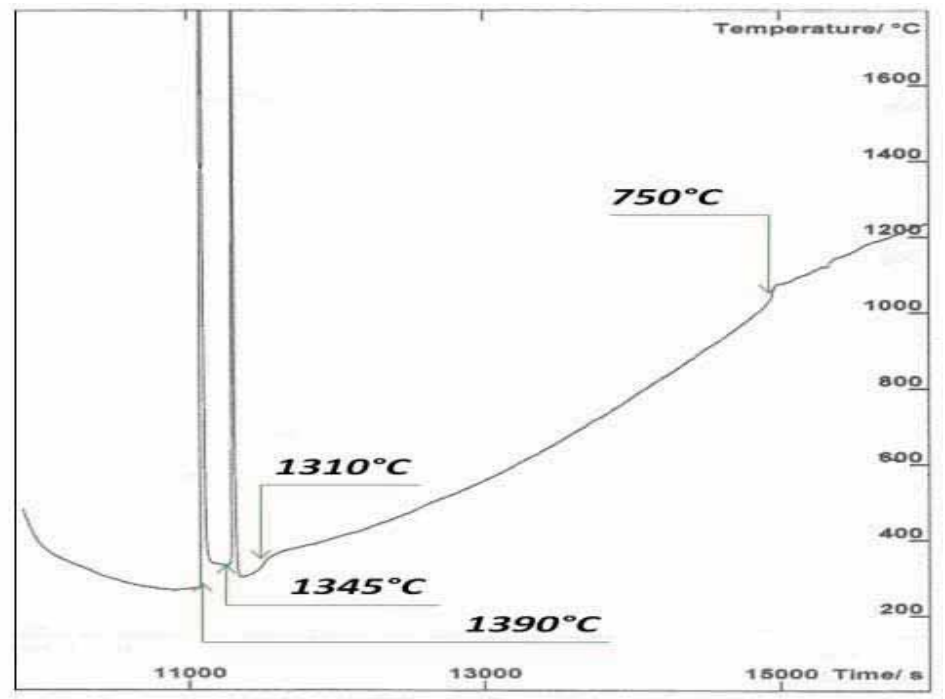

Figure 3: DTA curve of the alloy 2 on cooling with a heating rate of $10 \mathrm{~K} \cdot \mathrm{min}^{-1}$, showing four peaks at $1390^{\circ} \mathrm{C}, 1345^{\circ} \mathrm{C}$, $1310^{\circ} \mathrm{C}$ and $750^{\circ} \mathrm{C}$ 


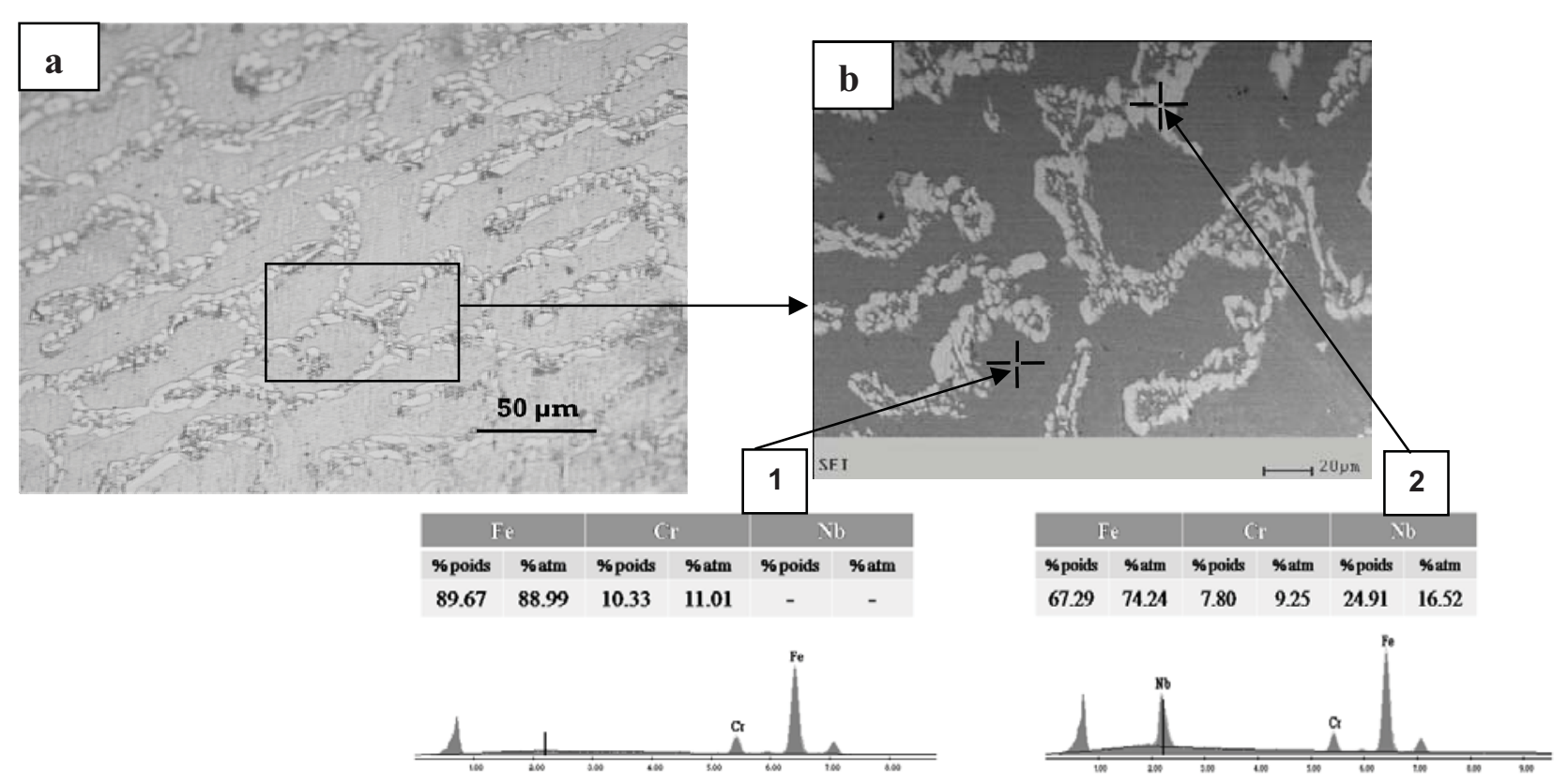

Figure 4: Alloy 2 SEM microstructure, EDS spectrum and semi-quantitative analysis from:

(1) Dark area, (2) clear area.

\subsection{Alloy 3 and 4}

Alloy 3 and alloy 4 exhibits the same behavior, so only results concerning the alloy 4 will be presented in this paper.

The DTA curve obtained for alloy 4 (fig. 5) reveals the presence of three exothermic peaks at $1405^{\circ} \mathrm{C}, 1390^{\circ} \mathrm{C}$ and $1340{ }^{\circ} \mathrm{C}$. The examination of solidification sequences and the microscopic observations (fig.6) allow us to suggest that these peaks correspond respectively to the reactions: $L \leftrightarrow \alpha$ (Fe-Cr), followed by the formation of a eutectic E3 at $1390{ }^{\circ} \mathrm{C}$, and eutectic E2: $\alpha+$ pseudo-binary or ternary Fe-Cr-Nb phase at $1340{ }^{\circ} \mathrm{C}$ However, we note the absence of the magnetic transition in this composition range.

The microstructure of this alloy (Fig. 6a) reveals the presence of tow eutectics:
- The eutectic E2 characterized by a lamellar morphology. The chemical analysis of white phase (EDS 1, Fig. 6b) reveals a composition of approximately $40 \%$ ironchromium and $60 \%$ niobium, which correspond to the pseudobinary $\mathrm{Nb}_{19}(\mathrm{FeCr})_{21}$ phase [7]. According to this result, we identified this E2 eutectic to the $\alpha$-solid solution (matrix) and variable stoichiometry of the pseudo-binary $(\mathrm{FeCr})_{\mathrm{x}} \mathrm{Nb}_{\mathrm{y}}$ phase.

- The second eutectic denoted E3, reveals the existence of two-phases precipitates in the matrix $\alpha$. The first phase rich in niobium (EDS 1, Fig. 6d) could be assigned to the crystallization of the $\mathrm{Nb}(\mathrm{FeCr})$ phase. The second phase (in the center), rich in iron (EDS 2, Fig. 6d) could correspond to the formation of a pseudo-binary phase $(\mathrm{Fe}-\mathrm{Cr})_{2} \mathrm{Nb}$.

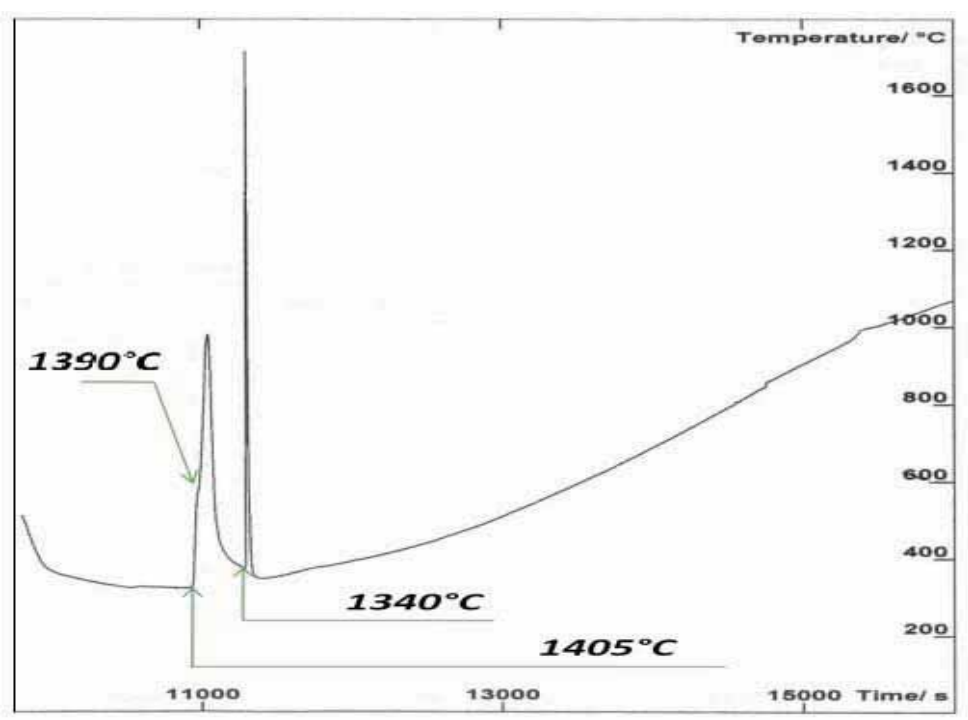

Figure 5: DTA curve of the alloy 4 on cooling, with a heating rate of $10 \mathrm{~K} \cdot \mathrm{min}^{-1}$. 

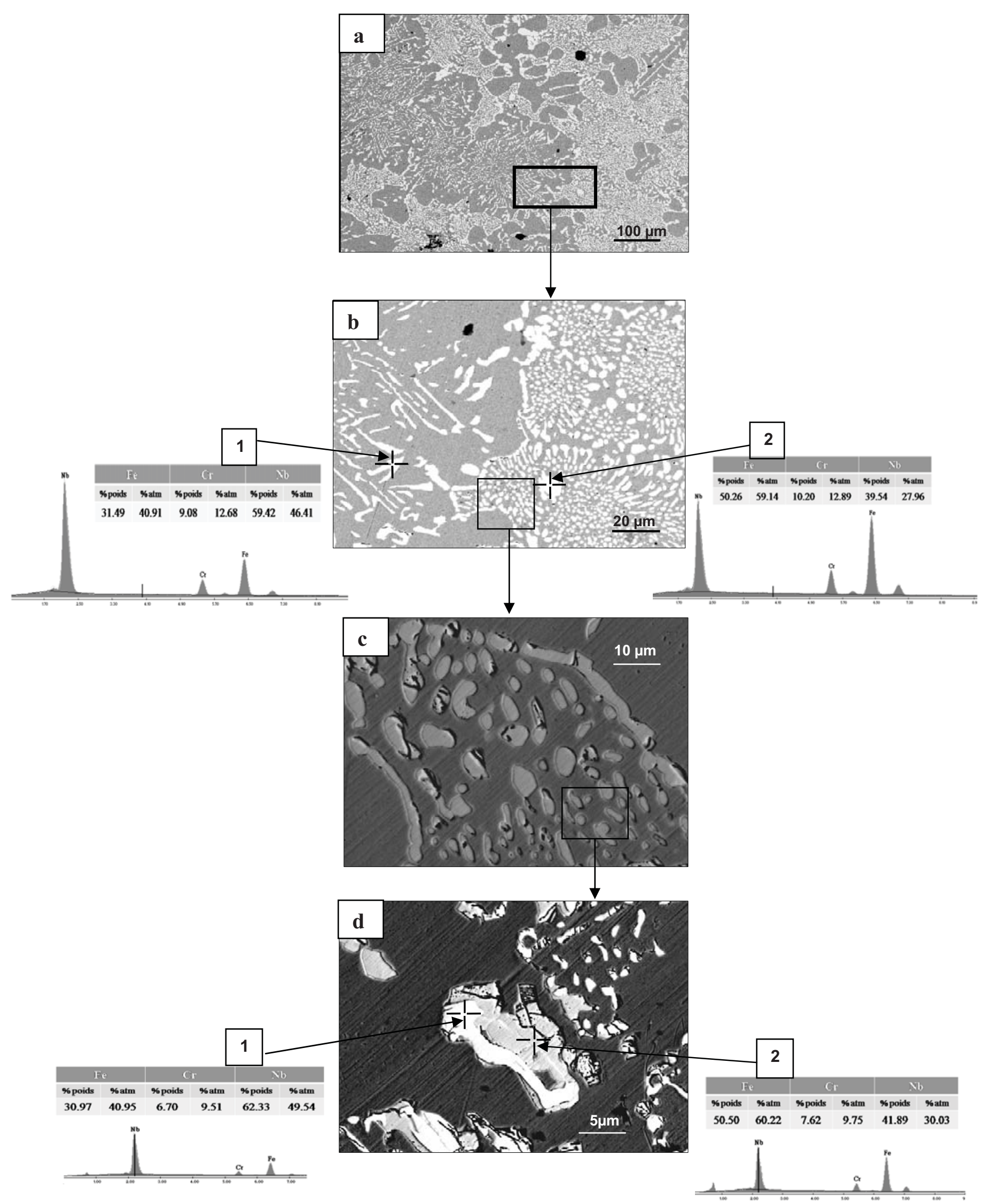

Figure 6: Alloy 4 SEM microstructure, EDS spectrum and semi-quantitative analysis from:

1) White area,

2) Light gray area. 


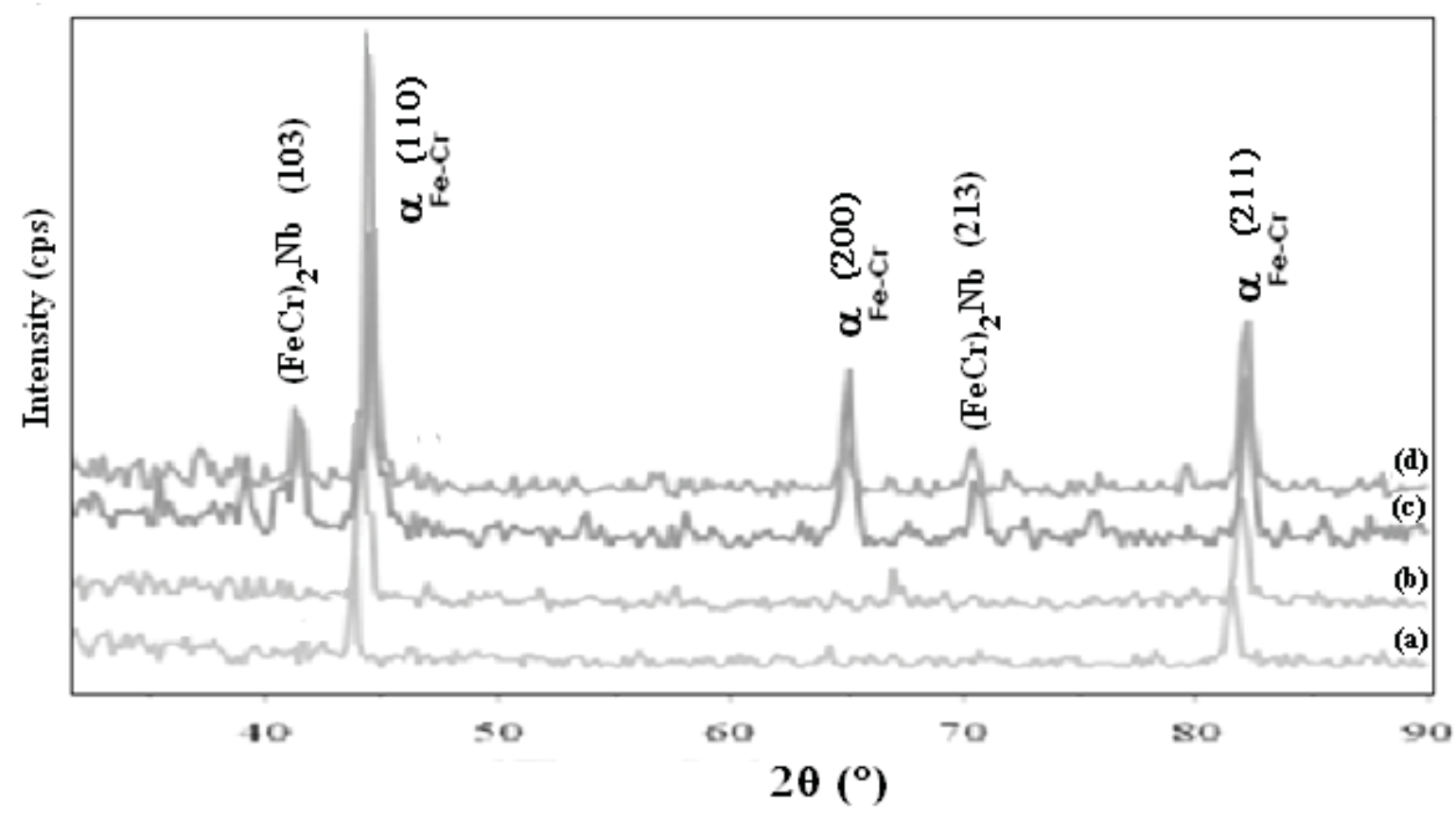

Figure 7: Superposition of X-ray diffraction patterns of the four alloys.

(a) Alloy 1,(b) Alloy 2, (c) Alloy 3, (d) Alloy 4.

\section{4 phase identification by XRD}

The superposition of the spectrum of X-ray diffraction of the four alloys (Fig.7) indicates the presence of the $\alpha$-solid solution, and confirms the enrichment of chromium in the matrix (table 1, from alloy 1 to alloy 4 ) by the shift of the peaks characteristic of the ferritic phase to the upper angle. This feature is due to chromium atomic radius smaller than that of iron and the presence of very small amount of niobium in the sample 1.

The presence of the $\alpha^{\prime}$-phase is not confirmed by the X-ray analysis diffraction in alloy 1 and 2 (Fig.7a, Fig.7b). The pattern of these alloys exhibits only the $\alpha$-solid solution. The two phases $\alpha$ and $\alpha^{\prime}$ crystallize in the same crystalline structure (centered cubic) type $\mathrm{CsCl}$ with lattice parameter very close, and therefore the choice of X-radiation, Co- $\mathrm{K}_{\alpha}$ or $\mathrm{Cu}-\mathrm{K}_{\alpha}$, would not distinguish $\alpha$ from $\alpha$ '. In our work conditions $\left(\mathrm{Cu}-\mathrm{K}_{\alpha}\right.$ ), it is impossible to distinguish between $\alpha$ and $\alpha$ '.

However, Samples 3 and 4 (Fig.7c, Fig.7d) indicate also the presence of the $(\mathrm{FeCr})_{2} \mathrm{Nb}$ phase.

\section{CONCLUSIONS}

The phase diagram of $\mathrm{Fe}-\mathrm{Cr}-\mathrm{Nb}$ compounds in the $\mathrm{Fe}$ rich region is investigated using DTA analysis, metallographic and $X$-ray diffraction. Some changes were observed and Based on the experimental results, the following conclusions can be made:

- The results obtained confirm that the $\alpha-(\mathrm{Fe}-\mathrm{Cr})$ solid solution, is the primary crystallization phase in all compositions shown in Table 1.

- According to the DTA results, the separation of the $\alpha$-solid solution in alloy 1 and 2 is suspected [9]. The phase transition

$\alpha$-solid solution $\leftrightarrow$ metastable $\alpha$-phase is seen in the temperature range between the magnetic transition and the $\alpha$-solid solution crystallization.

- The occurrence of two eutectics, E2 and E3, in equilibrium in alloys 3 and 4 is observed. The competition between theses eutectics, is seen for a higher composition ranging from 17 to 23 at. $\% \mathrm{Cr}$ and 7 to 8 at.\% $\mathrm{Nb}$.

\section{REFERENCES}

[1] Hald J., 1996, Metallurgy and creep properties of new 9$12 \%$ Cr steel, Steel Research, 67, 369-374.

[2] Zonfrillo G., Giovannetti I., Manetti M., 2008, Material selection for high temperature applications, Mecanica, 43, 125-136.

[3] Grujicic M., Tangrila S. and Cavin O.B., 1993, Effect of iron additions on structure of laves phases in $\mathrm{Nb}-\mathrm{Cr}-\mathrm{Fe}$ alloys, Materials Science and Engineering, A160, 37-48.

[4] Yamamoto K., Kimura Y., Wei F.G., Mishima Y., 2002, Design of Laves phase strengthened ferritic heat resisting steels in the $\mathrm{Fe}-\mathrm{Cr}-\mathrm{Nb}(-\mathrm{Ni})$ system, Materials Science and Engineering A329-331, 249-254.

[5] De Andradea T.F., Kliaugaa A.M., Plauta R.L.,Padilhaa A.F., 2008, Precipitation of Laves phase in a $28 \% \mathrm{Cr}$ $4 \% \mathrm{Ni}-2 \% \mathrm{Mo}-\mathrm{Nb}$ superferritic stainless steel, Materials Charaterisation 59,503-507

[6] Padilha A.F., Machado I.F., Plaut R.L., 2005, Microstructures and mechanical properties of $\mathrm{Fe}-15 \%$ $\mathrm{Cr}-15 \% \mathrm{Ni}$ austenitic stainless steels containing different levels of niobium additions submitted to various processing stages, Journal of Materials Processing Technology 170, 89-96.

[7] Brandes E.A., Brook G.B., 1992, Smithells Metals Reference Book, Seven Editions, ButterworthHeinemann, 11-210.

[8] Bonny G., Terentyev D., Malerba L., 2008, the $\alpha-\alpha^{\prime}$ missibility gap of $\mathrm{Fe}-\mathrm{Cr}$ alloys, Scripta materialia, 59, 1193-1196.

[9] Boutarek N., Mansour S., Amara S.E and Kesri R., 2008, Phase Transition in the Fe-V System, Int. J. Mat. Res. 99, N³, 301-306. 